\author{
A Master's Thesis \\ Presented to \\ The Graduate College of \\ Missouri State University
}

\author{
In Partial Fulfillment \\ Of the Requirements for the Degree \\ Master of Science, Psychology
}

By

Addie Wikowsky

August 2019 
Copyright 2019 by Addie Wikowsky 


\title{
EXPERTISE WITHIN WORKING MEMORY AND FLUID INTELLIGENCE
}

Psychology

Missouri State University, August 2019

Master of Science

Addie Wikowsky

\begin{abstract}
Working memory, fluid intelligence, and expertise are all psychological concepts that have been explored in the field. Working memory, defined by Baddeley (1986), is the temporary storage of stimuli presented to a person. The relationship between working memory and fluid intelligence is a common theme among studies. Fluid intelligence is one of the components of general intelligence $(g)$. Specifically, fluid intelligence can be described as being able to adapt thinking, even with no previous knowledge (Jaeggi, Buschkuehl, Jonides, \& Perrig, 2008). Expertise is another critical factor in these studies and is the acquisition of knowledge and being able to apply that knowledge (Chi, Glaser, \& Rees, 1982). This thesis looks at the inter-relationships of those concepts in Missouri State University psychology students. The researchers confirmed the previously noted relationship between working memory and fluid intelligence $(r=.50)$, but there were no other significant correlations between the tasks. It was interesting that working memory and fluid intelligence had similar correlations for the typing task $(r=.23, r=.19)$, although not significant. These effects disappeared after controlling for the data quality measures used in the study (i.e., ways to show the participants put effort into the study). More research is needed to confirm that the current measures of expertise, or different ones, are related to working memory or fluid intelligence.
\end{abstract}

KEYWORDS: working memory, fluid intelligence, expertise, automated operation span, advanced progressive matrices, typing task, correlations 


\title{
EXPERTISE WITHIN WORKING MEMORY AND FLUID INTELLIGENCE
}

By

Addie Wikowsky

\author{
A Master's Thesis \\ Submitted to the Graduate College \\ Of Missouri State University \\ In Partial Fulfillment of the Requirements \\ For the Degree of Master of Science, Psychology
}

August 2019

Approved:

Erin M. Buchanan, Ph.D., Thesis Committee Chair

Melissa D. Fallone, Ph.D., Committee Member

Dana C. Paliliunas, Ph.D., Committee Member

Julie Masterson, Ph.D., Dean of the Graduate College

In the interest of academic freedom and the principle of free speech, approval of this thesis indicates the format is acceptable and meets the academic criteria for the discipline as determined by the faculty that constitute the thesis committee. The content and views expressed in this thesis are those of the student-scholar and are not endorsed by Missouri State University, its Graduate College, or its employees. 


\section{ACKNOWLEDGEMENTS}

I would like to acknowledge the following people for their support during my undergraduate and graduate studies. I would first like to thank Dr. Erin Buchanan, as my advisor for the last two years, without her guidance this project would not have developed. Among this she has helped me understand more about practicing research and collaboration. In addition to her wit, she has also been incredibly supportive in all of the projects we have worked on together. She also has the crucial understanding of the necessity when breaks are needed.

Dr. Melissa Fallone and Dr. Dana Paliliunas for their continuous support with this thesis. They have guided me to be a better researcher, to watch mistakes as I write, to be mindful of how others may interpret my work.

Dr. Jon Mandracchia and Dr. Benjamin England, for without them I would not have contributed to research projects before starting my graduate studies.

I would also like to thank my supportive partner, Timothy Clark, as he has been my biggest support system throughout my education. He has supported both of us and has done so with a smile on his face. In addition to him I would like to thank our dogs, Elliot and Trout, because having them around throughout writing this has allowed me to take a break from the mundane to give them treats. 


\section{TABLE OF CONTENTS}

Introduction

Page 1

Literature Review

Page 2

Working Memory

Page 2

Fluid Intelligence

Page 3

Measuring Working Memory and Fluid Intelligence

Page 3

Expertise

Page 7

Interplay Between these Systems

Page 9

Method

Participants

Page 12

Materials

Page 12

Page 12

Procedure

Page 18

Results

Descriptive Statistics

Page 20

Hypothesis Tests

Page 20

Page 21

Discussion

Page 24

Conclusion

Page 25

References

Page 27

Appendix: Human Subjects IRB Approval

Page 30 


\section{LIST OF TABLES}

Table 1. Latin Square Order of Tasks for Non-Foreign Language

Page 19

Portion

Table 2. Latin Square Order of Tasks for Foreign Language Portion

Page 19 


\section{LIST OF FIGURES}

Figure 1. Letters of AOSPAN Presented to Participant

Page 13

Figure 2. Math Operation of AOSPAN Presented to Participant

Page 14

Figure 3. Example of APM

Page 15

Figure 4. Prompt used for Typing Test

Page 16

Figure 5. Example of Typing Test Results

Page 16

Figure 6. Example of a Foreign Language Placement Exam Question

Page 17

Figure 7. Point Breakdown of Placement Exam for Each Language

Page 18

Figure 8. Scatterplot to Show Correlation for AOSPAN and APM

Page 21

Figure 9. Scatterplot to Show Correlation for Typing Test and APM

Page 22

Figure 10. Scatterplot to Show Correlation for Typing Test and

Page 22 AOSPAN 


\section{INTRODUCTION}

There are many psychological studies looking at the relationship between working memory and fluid intelligence (Conway, Cowan, Bunting, Therriault, \& Minkoff, 2002; Shelton, Elliott, Matthews, Hill, \& Grouvier, 2010; Yuan, Steedle, Shavelson, Alonzo, \& Oppezzo, 2006). There are also many studies looking at working memory and expertise (Chase \& Simon, 1973; Chi, Feltovich, \& Glaser, 1981; Chi, Glaser, \& Rees, 1982). The gap in the literature is where working memory, fluid intelligence, and expertise are all examined thoroughly together. For this thesis, the relationship between working memory (as measured by the automated operation span task; AOSPAN) and fluid intelligence (as measured by the Advanced Raven's Progress Matrices) studies should be replicated to confirm previous findings of a correlation between the two constructs. In addition to this relationship, working memory and expertise (as measured by language and typing fluency) correlations will be reported to examine if there is a relationship, as previous research on chess and physics experts suggests (Chase \& Simon, 1973; Chi et al., 1981). Finally, the relationship between expertise and fluid intelligence will also be examined to see if the gap in the literature can be filled. Understanding the interplay between these cognitive systems is important because together they can demonstrate how the brain functions with different subject matters (e.g., whether or not someone is an expert in their field; whether someone can think abstractly) and circumstances (e.g., how someone would react or reason to a situation when presented to them). 


\section{LITERATURE REVIEW}

\section{Working Memory}

Working memory has been a large component to human cognition studies in the literature. Baddeley (1986) describes working memory as the temporary storage of stimuli being encoded. Working memory plays its biggest role as part of short-term memory (STM). STM, defined by Baddeley (1986), is the ability to hold a small amount of information for a limited time. STM works in an interacting system that serves higher level mental processes. These higher level mental processes include reasoning, problem solving, and learning.

Baddeley and Hitch (1994) first proposed a working memory model in 1974. Their model included the concept of a phonological loop, visuospatial sketchpad, and central executive. The phonological loop (previously the articulatory loop) has two parts: phonological storage and subvocal rehearsal. Phonological storage is when a person holds a sound memory trace until this trace is then rehearsed by the subvocal rehearsal of the model by repeating the trace internally. Baddeley and Hitch's memory model additionally includes a visuospatial sketchpad, which is primarily responsible for visual and spatial encoding. Visual encoding occurs when a person receives an incoming image or stimuli, and recognition processes are triggered in the brain so the person can respond appropriately. Baddeley and Hitch (1994) explain that the visuospatial sketchpad is a type of work space for incoming information. The final piece of Baddeley and Hitch's model is the central executive. The central executive is responsible for controlling when the phonological loop and visuospatial sketchpad are used, and how they interact with one another (Baddeley, 2002). The central executive can be compared traffic to a control officer, as it 
directs attention and resources to necessary tasks in the phonological loop and visuospatial sketchpad.

\section{Fluid Intelligence}

Various concepts of memory assist each other in order to improve the effectiveness of working memory. One construct is fluid intelligence $(g F)$. Jaeggi, Buschkuehl, Jonides, and Perrig (2008) classify $g F$ as a human ability that allows participants to adapt their thinking to the problem at hand regardless of acquired knowledge. In addition, Gray, Chabris, and Braver (2003) highlight that $g F$ is related to attentional control, or a person's ability to disregard any interference that could affect performance. Gray and colleagues (2003) also say that attentional control is necessary for the abstract thinking needed for $g F$. Horn (1968) reports that Cattell presented the idea of $g F$ in 1941 at an APA convention. Since then it has grown common in the behavioral sciences as a large portion of how general intelligence is measured.

\section{Measuring Working Memory and Fluid Intelligence}

Working memory has been tested in the field of psychology since Miller introduced the "magic number" in 1956. The magic number is the concept of how many single items we can hold in our memory. Miller (1956) suggested that we can hold seven items, plus or minus two (5 to 9). This research indicates why phone and social security numbers are grouped in smaller chunks, as that may be easier to remember. Working memory has recently been measured by two types of tasks outlined by Yuan and colleagues (2006), the two types are: simple memory-span and dual-trail tasks. 
Simple memory-span tasks measure short term memory by assessing a person's ability to recall a list of stimuli (e.g., words, numbers, or positions; Mathy, Chekaf, \& Cowan, 2018). Dual-trial tasks require that both processing and storage in the brain occur at the same time, compared to one at a time in simple-memory tasks. Conway and colleagues (2005) identified that the majority of working-memory measurements are considered dual-trail tasks because of their complexity. More modern working-memory measurements are often called complex-span tasks, because it is likely that more than two (i.e., dual) cognitive processes are occurring at the same time (Schmiedek, Hildebrandt, Lovden, Wilhelm, \& Lindenberger, 2009). This distinction between simple-span tasks and dual-trial tasks occurs because of the two components required for dual-trial tasks. For example, in a simple-span task, participants might be asked to repeat back a list of letters, while in a dual-trial task they would need to remember the letters (storage task) while also solving math problems (processing task).

One of the most used dual-trial tasks to measure working memory is the Operation Span (OSPAN) created by Turner and Engle (1989). In the OSPAN, the participant is given a math problem which they have to identify the solution as correct or incorrect (processing component) with a word or letter being presented after they answer. For example, a participant might answer "is 2 x $3+4=5$ ?" with FALSE, then be shown a letter or word after they say FALSE. The participant is then supposed to recall (storage component) those words after a few trials. In the original OSPAN task, a researcher sat with the participant and controlled the speed of the study (i.e., hit the spacebar to move between trials) and recorded the answers for each participant.

The original OSPAN and the automated OSPAN (AOSPAN; Unsworth, Heitz, Schrock, \& Engle, 2005) are the same task, but the AOSPAN is available completely online, without required researcher interaction to complete. This online presentation allows for less confounding 
variables between the researcher and the participant. The AOSPAN also has a practice period where the participant is presented with multiple math problems. After the math practice, they are given a sample trial of math problem where they are told to remember a letter after answering whether the math problem was true or false. After both practice portions are completed the participant then begins the real study. The participant must maintain $85 \%$ accuracy for the math operations in order for their data to be considered useful (i.e., good faith effort; Unsworth et al., 2005). After the task is completed, the researcher is given the participant's scores. The first is a raw score of the correctly recalled letters or words for each set. The researcher is also given a report on the participant's math errors to account for accuracy.

Daneman and Carpenter's (1980) Reading Span Task (RSPAN) is another example of a complex working-memory measurement. The authors originally had two ways of testing reading span. In the first part of the RSPAN, participants read sentences out loud to the experimenter. After the participant finished a few sentences, they had to recall the last word in each sentence in order. For the second part, Daneman and Carpenter (1980) had the participant read sentences that were from general knowledge, politics, and other subjects; while still trying to remember the last word. After reading the sentence, the participant had to identify if the statement was true or false. The experimenters were interested in if the participant had recalled the words in order or not for the reading span; however, the true/false verification increased the difficulty of the task, much like the math problems in the OSPAN task. The participants are scored on the number of correct words they recalled in the correct order. For example, the participant is supposed to recall the words: tent, shoe, and bottle. If the participant recalled shoe and bottle, they would receive two out of three points. It is important to note for this task that the order is crucial for scoring. For 
instance, if the participant recalled the same words as above in this order: shoe, tent, bottle, that participant would also receive two out of three points.

The N-Back task was created in the late 1950's (Kirchner, 1958). The idea behind this task was to measure short-term memory retention. It consists of different visual stages presented to the participant (Gajewski, Hanisch, Falkenstein, Thönes, \& Wascher, 2018). After a stimulus is presented, the participant is asked if it matches a stimulus that was presented $n$ trails before it. For example, if the stimulus was presented with letters, and this pattern was shown: A, B, D, A. The participant would have to identify if the 'A' was presented three trials back. This would be considered a 3-back task because of the number of stimuli in-between the two matching pieces. The stimuli would keep being produced, and the participant would need to keep identifying if the same stimuli was presented before. This process can be repeated with different difficulties, starting with 1-back, the researcher would just increase the number of stimuli between the two stimuli you would want the participant to match. The N-back is scored by the reaction times and percentage correct correlated to those in the same age group as the participant. This task challenges the participant because it requires encoding and updating of incoming stimuli while irrelevant stimuli are being introduced (Gajewski et al., 2018).

The Raven Progressive Matrices (RPM) is a measure of $g F$. Raven (1936) initially wanted to develop a test that would allow the researchers to interpret it without any social barriers, as compared to the criticisms of other standardized intelligence tests. In 1988, by Raven, Court, and Raven, it was updated and became the Raven's Advanced Progressive Matrices (APM; Bors \& Stokes, 1998). The participant is presented with several images that represent a complex pattern, and they must pick one of six or eight options that would complete the sequence. The images in the matrix may be rotated, flipped, or change in size. The APM consists 
of two sets compared to the original RPM which had five sets. Set one has 12 items and is generally used as practice for the participant. Set two has 36 items that is more difficult than set one. The participant is scored by how many of their answers were correct. These raw scores are then compared to percentiles based on the participants age. Researchers can also choose to use a time restriction, five minutes for set one or forty minutes for set two (Bors, \& Stokes, 1998). The time restrictions could be used as an assessment of intellectual efficiency, without the time restrictions it can be used to evaluate clear thinking.

To evaluate the relations in these tasks, Conway and colleagues (2002), presented a latent variable analysis between working memory, $g F, \mathrm{STM}$, and processing speed. In their study, they had participants complete multiple simple and dual-trial tasks including the OSPAN, RSPAN, and APM. They found that working memory and $g F$ were strongly correlated, and that working memory and STM were strongly correlated, but $g F$ was not linked to STM. The authors suggest that since working memory is correlated with STM and $g F$ is not, that working memory and $g F$ are different constructs that should be examined with distinct measurements.

\section{Expertise}

The last construct that may affect working memory or fluid intelligence is expertise. Chi and colleagues (1982) describe expertise as having an abundance of knowledge and having skill to apply that knowledge. The authors argue that having this knowledge and skill plays a large part in intelligence as a whole. Because participants are able to recall their skill better and faster, they are perceived as more intelligent. This effect has been demonstrated primarily with the skillsets of chess (Chase \& Simon, 1973) and physics (Chi et al., 1981). 
In Chase and Simon's (1973) study on chess and memory, they had three classes of participants who played chess. From highest to lowest skillset they were: master, Class A player, and beginner. The way the authors decided to study working memory was to isolate "chunks" that would then be encoded by the participant. These chunks were created by having a chess position set up having one of 28 variations. Chunks refer to Miller (1956) and his "magical number" 7 , in that chunks are information that is grouped together to ensure that memory can be kept at a reasonable number of objects. During the memory task the players were asked to recall different chess positions from memory (Chase \& Simon, 1973). The experimental design included two chess boards that were placed in front of the participant. These boards were recreated two ways. The first position presented to the participants, were played games that were arranged in the middle of a match and the second was from randomly placing the pieces on the board. The participant was told to examine the preset board for five seconds and recall the as much as they could remember on the full set board in front of them. The participant was able to repeat memorizing and recalling the board layout until they recalled the original set perfectly. It took those in the master class less trials than the Class A players and beginners to recreate the middle of the match positions. Those in the "master" class could encode the preset chess boards and recreate their model in less trials than the other two groups of participants, because they had more expertise playing chess. This finding suggests that the expertise influenced the results based on the position being a playable game or not.

Chi and colleagues (1981) looked at the same idea of expertise, but examined it with those in the field of physics. For their categories of participants, they used Ph.D. students in the physics department (experts) and undergraduates who had only completed one semester of a physics course (novices). They were given 24 problems to group together by the how the 
solution to the problem was to be found. All participants were interviewed after they separated the problems to their respective categories to see how they reasoned why that problem fits with the category they chose. They determined that the experts sorted by the laws of physics, and the novices sorted by surface structures. These surface structures refer to objects, terms, or configurations of the problem presented.

In the second part of the study, the experts and novices were presented a new set of 20 physic problems. This part of the study also included an intermediate participant who was a fourth-year physics major. These problems were created to include both physic laws and surface features combined to see how the participants would categorize them. The results were replicated from the previous study by the expert and the novice participants. Yet, the intermediate participant reasoned both by using the laws of physics and surface structures, showing that they had applied the laws, but not yet left the surface structure. These studies by Chase and Simon and Chi and colleagues, demonstrate that expertise is perceptually learned through practice and understanding. They both demonstrate ideas of chunking (working memory) and previous knowledge (intelligence) that can lead to expertise.

\section{Interplay Between these Systems}

Working memory, $g F$, and expertise each play a role in how we view the world around us and evaluate everyday situations. Shelton and colleagues (2010) found that working memory was a predictor for $g F$. The authors did so by looking at multiple working memory and $g F$ tests and seeing how they correlated with processing speed, primary and secondary memory, working memory, and $g F$. After running a structural equation model (SEM), they found that processing speed, primary and secondary memory, and working memory all correlated with $g F$. They 
looked further into their SEM model to examine at how much of the variance in $g F$ was explained by working memory. The authors found that working memory had a unique variance when it came to predicting $g F$ that none of the other constructs had. This supports that working memory is primary component of $g F$.

Grabner, Neubauer, and Stern (2006) looked at the impact of intelligence and expertise on performance and neural efficiency. The authors recruited chess players for their study. The participants had to complete psychometric tests which included: the NEO-Five-Factor-Inventory, state anxiety test, a mood questionnaire, and the Intelligenz-Struktur-Test $2000 \mathrm{R}$ for cognitive ability (Amthauer, R., 2001). These psychometric tests were used as a control for the EEG data collected. The participants also had to complete a speed, memory, and reasoning task using different types of chess boards and pieces on a computer while being monitored by an EEG. The authors found that the more intelligent participants had better performance than less intelligent participants in chess overall. However, those who were an expert at the task (chess in this study), performed well despite lower measured intelligence in other circumstances.

The study outlined in this paper will look at how working memory, $g F$, and expertise correlate with one another. There have been multiple studies published on the relationship between working memory and expertise, but few on the relationship between $g F$ and expertise. The hypothesis in this study is that greater expertise (as measured by foreign language or in typing), will correlate with higher working memory AOSPAN scores and higher fluid intelligence APM scores. The researchers believe that those who have higher working memory scores and higher $g F$ scores, will then demonstrate greater expertise. This study will also look at the relationship between working memory and $g F$ to confirm the positive relationship, as others have identified (Conway et al., 2002; Shelton et al., 2010; Yuan et al., 2006). The multiple ways 
these components interact is important because it shapes overall learning experiences and everyday critical thinking. Expertise works alongside working memory and $g F$ because it is needed to be able to recall and think about new problems at hand that the expert is evaluating. Without all three components it would be difficult for people to finish work efficiently, and by looking at these three components together, the field of psychology may be able to achieve a better understanding of how working memory, $g F$, and expertise interact. The purpose of the present study is to examine the relationship among working memory, $g F$, and expertise as measured by the AOSPAN, APM, and using a typing test or foreign language placement exam on college students enrolled in an introductory or upper level psychology course. 


\section{METHOD}

\section{Participants}

This study received IRB approval (IRB-FY2018-750) September $5^{\text {th }}$, 2018. Participants were recruited from the Introductory Psychology courses and an upper level Psychology course at Missouri State University. There were two studies for the participants to choose from, an Expertise Study and an Expertise Study with a Foreign Language requirement. If the participant was either in the introductory course or the upper level course, they could participate in either section. If any of the participants had taken two years of French, German, or Spanish in either high school or college, they were eligible to participate in the Expertise Study with a Foreign Language requirement, but they could select the non-foreign language option if desired. All participants either received course credit or extra credit for their participation in this study. There was a total of 48 participants in both studies. There were only six participants in the foreign language section. Of those six participants, one had taken two years or more of French, one had taken two years or more of German, and four had taken two Spanish.

\section{Materials}

Automated Operation Span (AOSPAN). The AOSPAN was accessed through a Missouri State University domain. The AOSPAN consisted of three portions, two for practice: one of the letter recalls, the second with math problems, and last the full AOSPAN problems. The participant was prompted with the instructions explaining they will have to memorize letters and solve simple math problems. During the practice letter recall, they were shown black bold letters and told to remember the order in which they appear (Figure 1). For the math practice, 
they were given a math operation and told to identify whether the solution was true or false. For example, "IS $2 \mathrm{X} 3+4=10$ " would be indicated as TRUE (Figure 2). After the practice portions, the participant then is prompted with the AOSPAN instructions where they were told after they make their decision about whether the math operations answer is true or false, and that they must try to remember the letter that follows. The participant is told that it is important for them to answer the math operations quickly and accurately and must answer at least $85 \%$ of the problems correctly. The percent correct was displayed on the screen. There are 75 math problem and letter combinations, shown in sets of 2 to 7 problems with letter recall. To recall the letters, participants clicked on letters in order after the last problem-letter set. Participants were scored by the number of letters they correctly recalled, and scores can range from 0 to 75 . Participants who did not score $85 \%$ were not be used in the study.

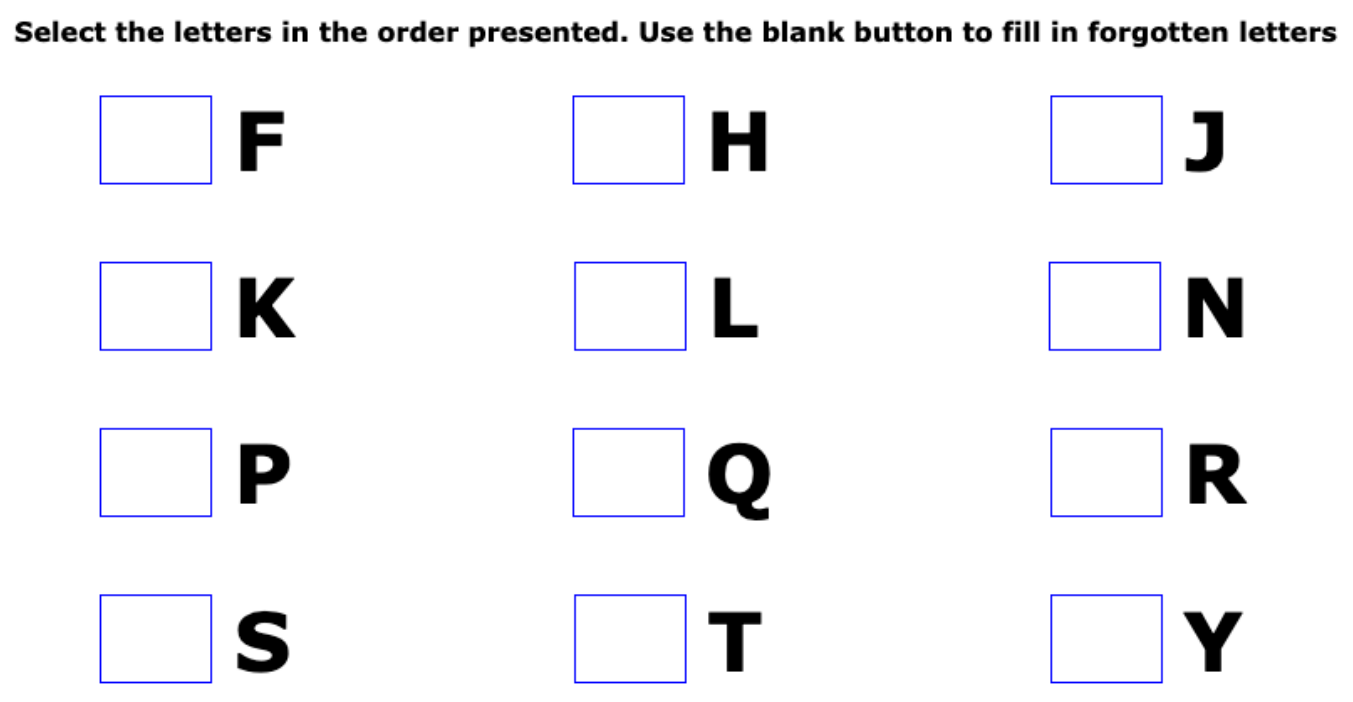

blank

Figure 1. Letters of AOSPAN Presented to Participant: This screen demonstrates where the participant would indicate the order of the presentation of the letters after the math problem has been answered. 


\section{$(1 * 2)+1$}

\section{When you have solved the math problem, click the mouse to continue.}

Figure 2. Math Operation of AOSPAN Presented to Participant: This screen shows an example of the math operations presented to the participant.

Advanced Raven Progressive Matrices (APM). The APM was administered through a Qualtrics survey for easier access. It consisted of three practice demonstrations. For example, in Figure 3, the participant saw eight patterns that build on one another and then a blank box. They were told to complete the pattern by choosing one the eight patterns below the image that best fits the original pattern. Below that image is eight possible options that could complete the pattern. Since this is a practice problem, the participant was told that numbers 4,6 , and 7 cannot be correct because they only show one circle. The participant was also told that numbers 1,3 , and 5 cannot be correct because they only show two circles. The last thing they were told is that number 2 cannot be correct because it has too many circles. This leaves number 8 to be the correct option. All 36 matrices reflect this type of abstract thinking. After the participant completed the practice demonstrations, they started the APM. For the APM, it was required of the participant that they answer the current question before moving onward to the next. The 
participants completed set two of the APM, containing 36 problems and they had 25 minutes to complete it. Scores can range from 0 to 36 .

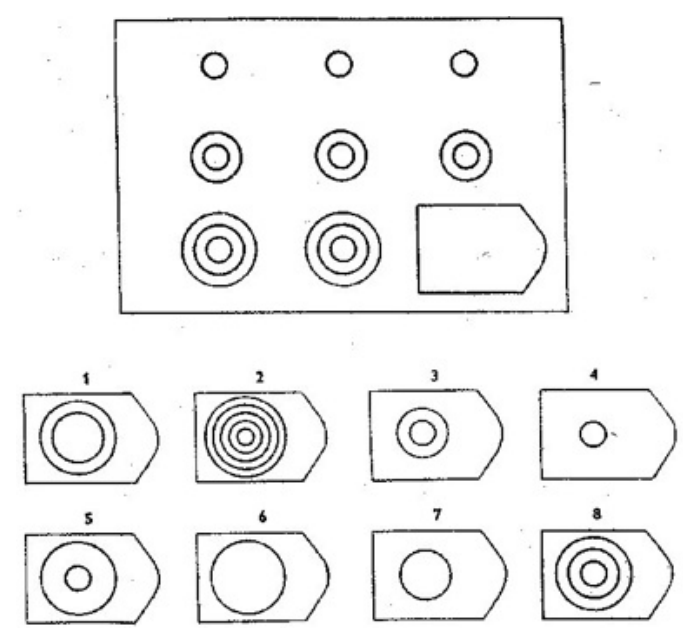

Figure 3. Example of APM: This is the practice problem included in the instructions for the APM.

Typing Task. The typing task is a words-per-minute typing task administered to all participants. It is a demonstration of expertise for those who do not have any foreign language experience. For this task, we used an online typing task (www.TypingTest.com). The participant completed a 1-minute typing test from this website. There were multiple choices of typing tests prompts to choose from, and the participants were instructed to choose the "Rules of Baseball" option. The participants had one minute to type as quickly and accurately as possible. Figure 4 demonstrates the prompt participants had to type. The timer started as soon as the participant began typing. The website keeps track of any typing errors the participant may have committed. Figure 5 shows an example of the participant's raw typing speed, errors, and adjusted speed. Their typing speed is based on words per minute. 


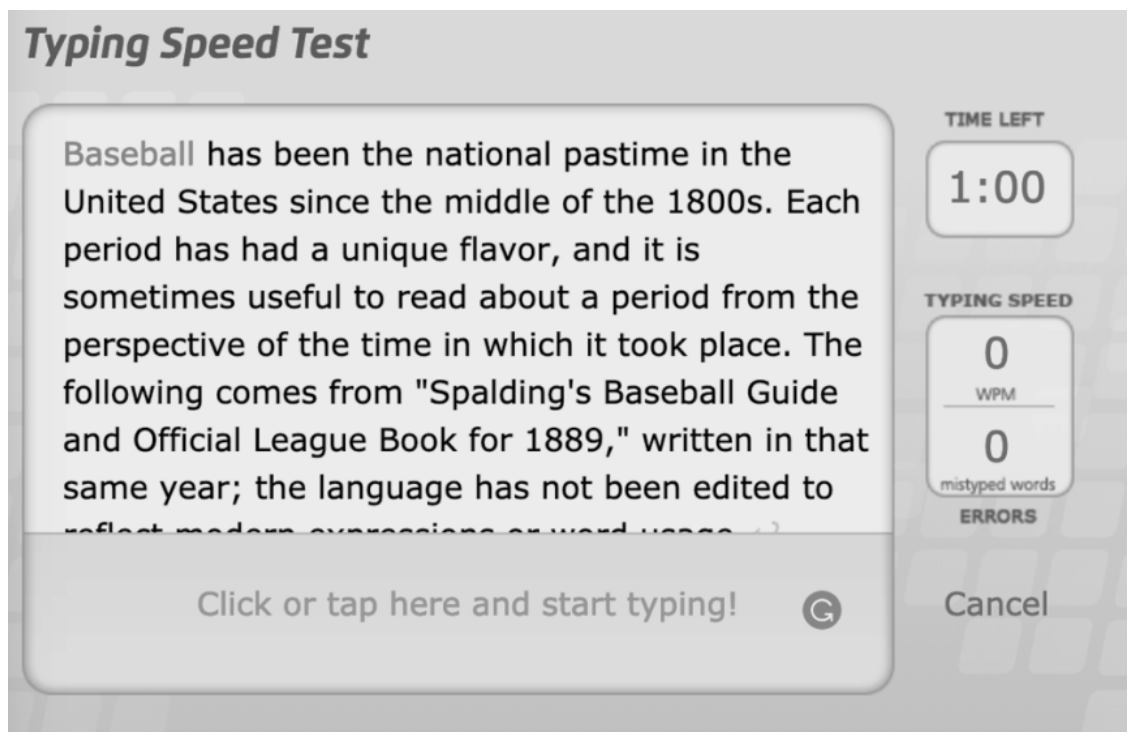

Figure 4. Prompt used for Typing Test: This figure is part of the prompt all participants had to type verbatim.

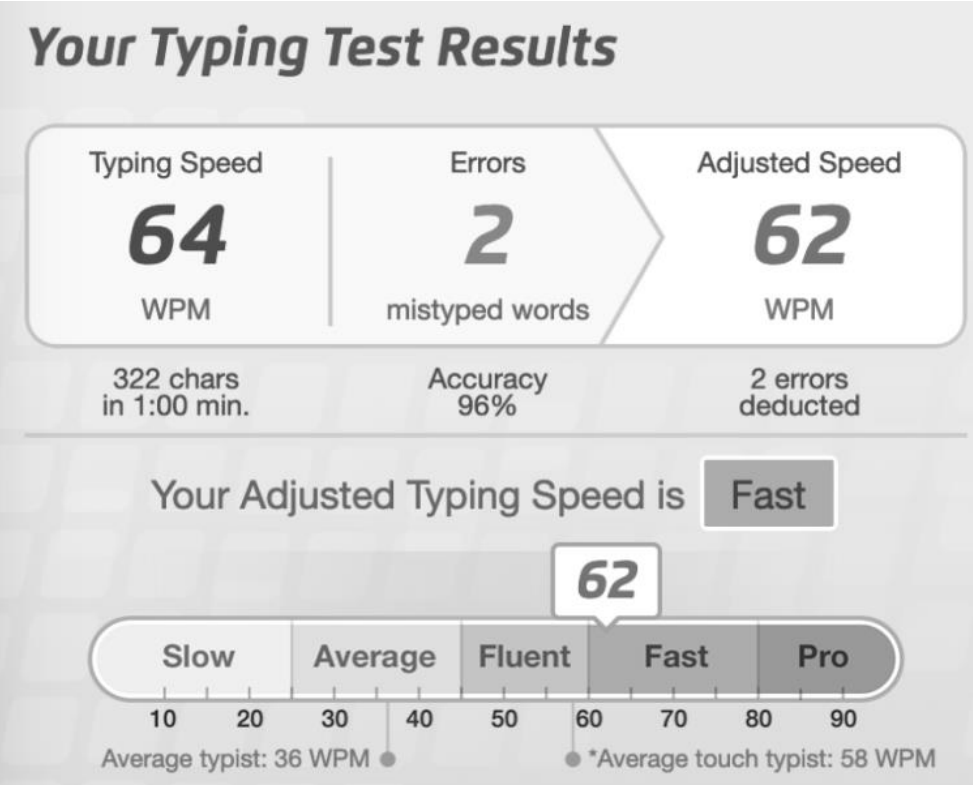

Figure 5. Example of Typing Test Results: This figure shows the participants typing speed, errors, and adjusted speed.

Foreign Language Placement Exam. This task was to explore expertise in an additional measure other than typing, which is often used in the literature (Beilock \& Holt, 2007) for ease 
of measurement and access to more participants. Participants would sign up for the foreign language portion if they desired. In addition to taking the typing task, the participants were also required to take Missouri State University’s Foreign Language Placement Exam given to those who wish to enroll in a foreign language course. The placement exam demonstrated proficiency in French, German, or Spanish. The entire exam was computerized and evaluates grammar, vocabulary, and reading comprehension in the above languages. For the reading comprehension questions, the participant was given a prompt, in the foreign language they know, and had to answer a question about it (Figure 6). After the exam was completed, they were given a score that represents which section of that language they should take (i.e., 101, 102, 201, 202 representing the four-course sequence of foreign language requirement), and the point totals will be used as our measure of expertise (Figure 7). These scores will be translated into z-scores to be able to use a standardized metric for language expertise overall.

Read the selection and mark the letter of the best answer to the question.

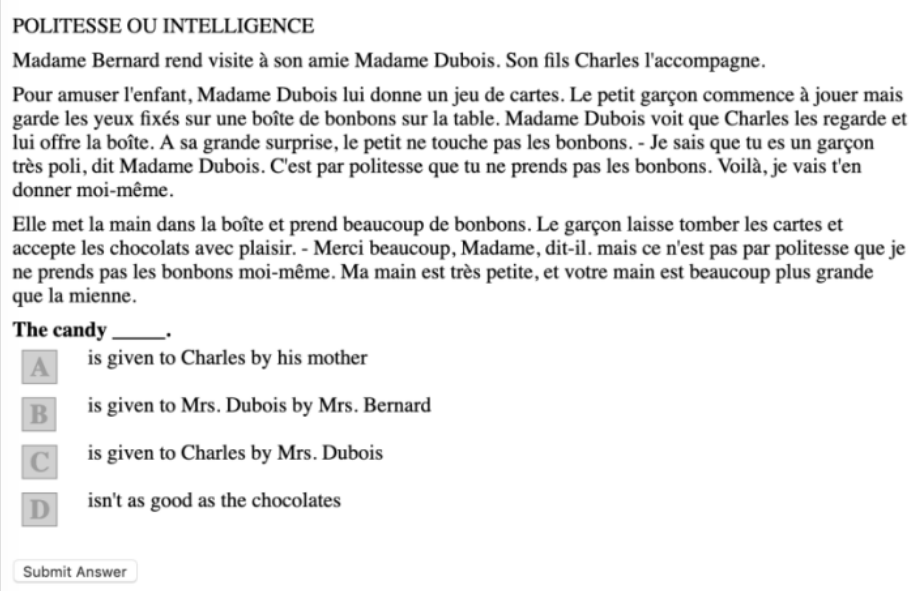

Figure 6. Example of a Foreign Language Placement Exam Question 
Points: 0

Placement:

\begin{tabular}{|l|l||}
\hline below 265 & French 101 \\
\hline $265-333$ & French 102 \\
\hline \hline $334-380$ & French 201 \\
\hline \hline above 380 & French 202 \\
\hline
\end{tabular}

\section{Points: 0}

\section{Placement:}

\begin{tabular}{||l|l|}
\hline below 327 & German 101 \\
\hline $327-407$ & German 102 \\
\hline \hline $408-531$ & German 201 \\
\hline \hline above 531 & German 202 \\
\hline
\end{tabular}

\section{Points: 0}

\section{Placement:}

\begin{tabular}{|l|l|}
\hline below 275 & Spanish 101 \\
\hline $275-345$ & Spanish 102 \\
\hline \hline $346-425$ & Spanish 201 \\
\hline \hline above 425 & Spanish 202 \\
\hline
\end{tabular}

Figure 7. Point Breakdown of Placement Exam for Each Language: These images demonstrate the amount of available points and the corresponding course the participant should take. In the following order are the points and sections assigned to that range of points for: French, German, and Spanish.

\section{Procedure}

Sessions were administered in groups of 1-24, dependent on how many participants had signed up for each time slot. All tasks were given to each participant during a session in the same order; however, the order was counterbalanced between sessions using a Latin square. Each session lasted for roughly 60 minutes, unless the participant had signed up for the foreign language session in which it took them approximately 90 minutes. The session with the foreign language placement exam started in this order: AOSPAN, APM, typing task, placement exam. 
The next scheduled session performed the tasks in this order: placement exam, AOSPAN, APM, typing task. The rest of the session followed different variations of these until all listed combinations had been completed by the participants and the experimenter started over (Table 1 and Table 2). The session without the placement exam started in this order: APM, typing task, AOSPAN. The next session that came in for this task performed them in this order: AOSPAN, APM, typing task. This Latin square design was used until all combinations had been performed by different groups of participants. By counterbalancing each group, we were able to balance potential carry over or fatigue effects for each session and time slot.

Table 1. Latin Square Order of Tasks for Non-Foreign Language Portion: This table demonstrates the order of tasks the participant completed in the non-foreign language section of the study.

\begin{tabular}{ccc}
\hline $\begin{array}{c}\text { Non-Foreign Language } \\
\text { Session 1 }\end{array}$ & Non-Foreign Language & Non-Foreign Language \\
Consent Form & Session 2 & Session 3 \\
APM & Consent Form & Consent Form \\
Typing Test & AOSPAN & Typing Test \\
AOSPAN & APM & APM \\
\hline
\end{tabular}

Table 2. Latin Square Order of Tasks for Foreign Language Portion: This table shows the order of tasks completed by the participant in the foreign language section of the study.

\begin{tabular}{cccc}
\hline Foreign Language & Foreign Language & Foreign Language & Foreign Language \\
Session 1 & Session 2 & Session 3 & Session 4 \\
\hline Consent Form & Consent Form & Consent Form & Consent Form \\
AOSPAN & Placement Exam & Typing Test & APM \\
APM & AOSPAN & Placement Exam & Typing Test \\
Typing Test & APM & AOSPAN & Placement Exam \\
Placement Exam & Typing Test & APM & AOSPAN \\
\hline
\end{tabular}




\section{RESULTS}

\section{Descriptive Statistics}

There were 35 participants who scored at least $85 \%$ on the math portion of the AOSPAN, a measure to indicate data quality or effort. The mean score on the AOSPAN for those participants was $51.97(S D=15.55)$ and the scores ranged from 10 to 75 . The math accuracy of the AOSPAN for these participants resulted in a mean of 93.06, $(S D=4.75)$. The typing test had a mean of $46.68(S D=15.23)$, with a range of $13-85$ words per minute (WPM). The APM had a mean of $15.81, S D=6.17$, with the highest score of 26 and a lowest score of 3 . There were six participants who completed the foreign language placement exams. One participant completed the French placement exam, one participant completed the German placement exam, and four participants completed the Spanish placement. For the French placement exam the participant scored 32 points. For the German placement exam the participant scored 238 points. Lastly, the Spanish placement exam participants points scored are: 160, 152, 141, 851. All of these fell into the range for placement in the introductory course for their second language, with the exception of the Spanish placement exam participant who scored an 851 which placed them in range for the fourth Spanish course in the sequence.

Descriptive statistics were also calculated on the entire set of participants who completed the study $(N=48)$. The mean for the APM would have decreased to $14.25(S D=6.59)$. The AOSPAN scores also decreased $(M=48.09, S D=16.71)$. As a result, the math accuracy also decreased on the AOSPAN as a result of examining all participants $(M=87.09, S D=13.31)$. 


\section{Hypothesis Tests}

Since there were only six participants who completed the foreign language placement exam, the expertise hypotheses associated foreign language scores was not analyzed due to the low sample size. Instead, the typing test for all participants was used as the measure of expertise. Therefore, three correlations were calculated on the entire dataset of participants $(N=48)$. The first was to confirm the relationship between the APM and the AOSPAN, $r=.50 .95 \%$ CI $[.24$, $.70], p<.001, R^{2}=.25$ (Figure 8). This finding confirms that $g F$ and working memory were positively correlated, as shown in previous research (Conway et al., 2002; Shelton et al., 2010). The second correlation analyzed was the typing test score and the APM score, and the correlation was not significant, $r=.19,95 \%$ CI [-.11,.47], $p=.21, R^{2}=.04$ (Figure 9). The final correlation observed was the AOSPAN and the typing test scores, and this correlation was also not significant, $r=.23,95 \%$ CI $[-.08, .50], p=.15, R^{2}=.05$ (Figure 10).

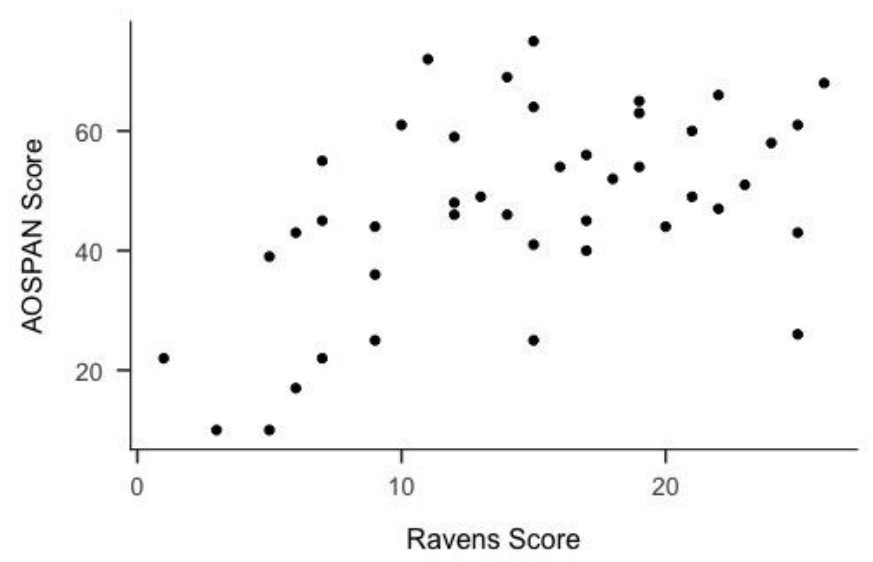

Figure 8. Scatterplot to Show Correlation for AOSPAN and APM: This scatterplot demonstrates the correlation between the AOSPAN scores and the APM. 


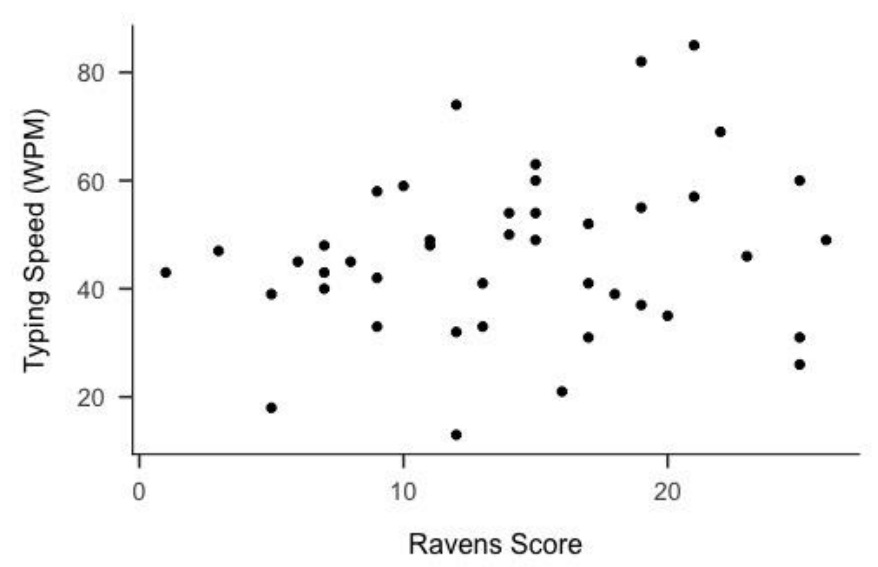

Figure 9. Scatterplot to Show Correlation for Typing Test and APM: This scatterplot shows the correlation between the typing test and the APM.

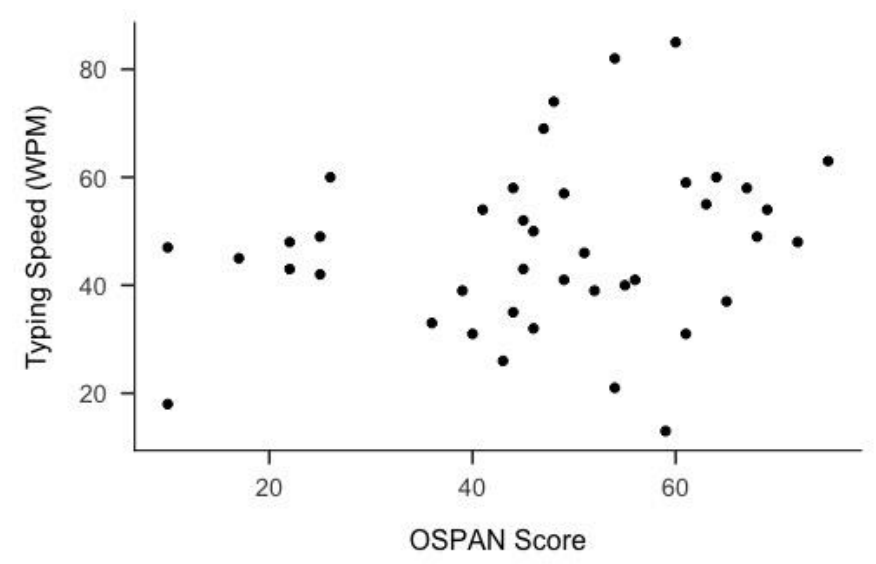

Figure 10. Scatterplot to Show Correlation for Typing Test and AOSPAN: This scatterplot shows the correlation between the typing test and the AOSPAN.

Since over a quarter of the sample did not perform the math portion to the recommended $85 \%$, we performed regression models using the math score as a covariate to determine the relation $(\mathrm{pr})$ between variables controlling for math performance on the complete set of participants. The first regression model was the APM predicted by the AOSPAN's letter recall score and math accuracy, $F(2,40)=7.99, p=<.001, R^{2}=.29$. The partial correlation of AOSPAN and APM was .39. The second regression model was the typing score predicted by the 
AOSPAN's letter recall and math accuracy, $F(2,38)=1.31, p=.27, R^{2}=.07$. The partial correlation of the typing test and AOSPAN letter recall and math accuracy was .15. Since the APM scales did not depend on math accuracy, no regression was necessary to determine a partial relationship between APM and the typing test.

Given the potential low effort from participants who did not complete the AOSPAN with $85 \%$ accuracy, we also examined the correlation between our three variables for the smaller subset of participants $(N=35)$. The correlation between the APM and the AOSPAN was significant, $r=.46,95 \% \mathrm{CI}[.14, .70], p=.006, R^{2}=.21$. The correlation between the typing test and APM was not significant, $r=.08,95 \% \mathrm{CI}[-.28, .42], p=.67, R^{2}=.006$. The final correlation between the AOSPAN and the typing test was also not significant, $r=.12,95 \%$ CI [$.23, .46], p=.48, R^{2}=.01$.

The original power analysis was based on an a priori correlation with two tails. We hoped for an effect size of $.30\left(r^{2}=.09\right)$, at $80 \%$ power, and alpha $=.05$. Using G*Power (Faul, et al., 2007), this analysis yielded a sample size of 82 participants. However, when a power analysis was examined a posteriori, controlling for our average correlations for the typing test and the APM $(r=.19)$ and the AOSPAN and typing test $(r=.23)$, approximately 145 participants were needed to detect a significant relationship between these correlations at alpha < .05 


\section{DISCUSSION}

Expertise and working memory studies have been performed focusing on various psychological research topics. Very few studies, however, include $g F$ and its relationship to expertise. This study was designed to compare expertise and working memory again, and then see how expertise and fluid intelligence are related. The original hypothesis was that those who have a higher expertise in foreign language or in the typing task will have a higher working memory AOSPAN scores and higher fluid intelligence APM scores.

First, we replicated the correlation between working memory and fluid intelligence showing $r=.50, p r=.39$ controlling for math scores. This demonstrates that the relationship is positive and strong, while controlling for math accuracy. Next, we extended these correlations to expertise. The correlation for the APM and typing test was $r=.19$, and the correlation for the AOSPAN and the typing test was $r=.23$, with a of $p r=.15$. These results do not indicate support for our hypothesis that expertise and working memory or fluid intelligence are significantly related; however, the limitation of small sample size should be considered. Our sample size was not as large as it needed to be to have sufficient usable data for all parts of the experiment. For example, only six participants completed the foreign language as an expertise part of our study, mostly scoring into the introductory course for their language. More variability and scores would be necessary to fully examine this variable.

An additional reason for these low correlations between the APM, AOSPAN, and typing as an expertise could be because typing does not demonstrate having an abundance of knowledge but does apply to using a skill (Chi, Glaser, \& Rees, 1982). If a different form of expertise could be used instead of typing, such as those used in previous studies (e.g., chess or physics), these 
correlations could have been stronger or significant. Future studies could this experiment with a larger sample size and a different form of expertise (secondary language, chess, or physics). The original correlations in this study showed a relationship between the AOSPAN and APM ( $r=$ .50). The typing test did not correlate with the APM $(r=.19)$ or the AOSPAN $(r=.23)$. Working memory and $g F$ were not completely correlated, which indicates the divergent nature of their constructs. Given their differences, it is interesting that their correlations with the typing task were almost the same and not very strong. The lack of correlation between expertise in this study with working memory and gf may be related to the measurement of expertise through typing. Perhaps using a different form of expertise that focuses on knowledge and application, instead of just typing, we could have used a more precise form of expertise.

\section{Conclusion}

Other researchers may find that expertise is related to different areas of memory; for example, in short-term or long-term memory. They may also find expertise relates to different areas of intelligence besides fluid intelligence, such as crystalized intelligence or general knowledge. Previously stated by Grabner, Neubauer, and Stern (2006), those who were more intelligent (using the Intelligenz-Struktur-Test 2000 R; Amthauer, R., 2001) performed better than those who had less intelligence, with the exception of those who were experts at the task (chess).

In this study, the only significant finding was additional support that working memory and $g F$ are positively correlated. However, there may be others who find this research helpful in their work, as null results can be informative or else we start to create a file drawer problem. The file drawer problem (Rosenthal, 1979), where the papers in behavioral sciences that did not have 
significant results $(p>.05)$ were not getting published. In turn, this caused those papers with Type I errors to get published even with irrelevant effect-size estimations. This correlational study demonstrates that more research needs to be established with expertise and could be helpful to those researchers examining these constructs. 


\section{REFERENCES}

Amthauer, R., Brocke, B., Liepmann, D., \& Beauducel, A. (2001). Intelligenz-Struktur-Test 2000 R. Göttingen: Hogrefe, 2.

Baddeley, A. D., (1986). Working memory. Oxford: Clarendon Press.

Baddeley, A. D., (2002). Is working memory still working? European Psychologist, 7(2), 85-97. doi: $10.1027 / / 1016-9040.7 .2 .85$

Baddeley, A. D., \& Hitch, G. J. (1994). Developments in the concept of working memory. Neuropsychology, 8(4), 485-493. doi: 10.1037/0894-4105.8.4.485

Beilock, S. L., \& Holt, L. E., (2007). Embodied preference judgements: Can likeability be driven by the motor system? Psychological Science, 18(1), 51-57. doi: 10.1111/j.14679280.2007.01848.x

Bors, D. A., \& Stokes, T. L. (1998). Raven's advanced progressive matrices: Norms for first-year university students and the development of a short form. Educational and Psychological Measurement, 58(3), 382-398. doi: 10.1177/0013164498058003002

Chase, W. G., \& Simon, H. A., (1973). Perception in chess. Cognitive Psychology, 4(1), 55-81. doi: 10.1016/0010-0285(73)90004-2

Chi, M., Feltovich, P., \& Glaser, R., (1981). Categorization and representation of physics problems by experts and novices. Cognitive Science, 5(2), 121-152. doi:

$10.1207 / \mathrm{s} 15516709 \operatorname{cog} 0502 \_2$

Chi, M., Glaser, R., \& Rees., E. (1982). Expertise in problem solving. In R. J. Sternberg (Ed.), Advances in the Psychology of Human Intelligence, (Vol. 1). Hillsdale, NJ: Erlbaum.

Conway, A. R. A., Cowan, B., Bunting, M. F., Therriault, D. J., \& Minkoff, S. R. B., (2002). A latent variable analysis of working memory capacity, short-term memory capacity, processing speed, and general fluid intelligence. Intelligence, 30, 163-183. doi: $10.1016 / \mathrm{s} 0160-2896(01) 00096-4$

Conway, A. R. A., Kane, M. J., Bunting, M. F., Hambrick, D. Z., Wilhelm, O., Engle, R. W., (2005). Working memory span tasks: A methodological review and user's guide. Psychonomic Bulletin \& Review 12(5), 769-786. doi: 10.3758/BF03196772

Daneman, M., \& Carpenter, P. A., (1980). Individual differences in working memory and reading. Journal of Verbal Learning and Verbal Behavior, 19(4), 450-466. doi: $10.1016 / \mathrm{S} 0022-5371(80) 90312-6$ 
Faul, F., Erdfelder, E., Lang, A.-G., \& Buchner, A. (2007). G*Power 3: A flexible statistical power analysis program for the social, behavioral, and biomedical sciences. Behavior Research Methods, 39, 175-191. doi: 10.3758/bf03193146

Gajewski, P. D., Hanisch, E., Falkenstein, M., Thönes, S., \& Wascher, E., (2018). What does the $n$-Back task measure as we get older? Relations between working-memory measures and other cognitive functions across the lifespan. Frontiers in Psychology, 9, 2208. doi:10.3389/fpsyg.2018.02208

Grabner, H. R., Neubauer, A. C., \& Stern, E. (2006). Superior performance and neural efficiency: The impact of intelligence and expertise. Brain Research Bulletin, 69, 422439. doi: 10.1016/j.brainresbull.2006.02.009

Gray, J. R., Chabris, C. F., \& Braver, T.S (2003). Neural mechanisms of general fluid intelligence. Nature, 6(3), 316-322. doi: 10.1038/nn1014

Horn, J. L. (1968). Organization of abilities and the development of intelligence. Psychological Review, 75(3), 242-259. doi: 10.1037/h0025662

Jaeggi, S. M., Buschkuehl, M., Jonides, J., \& Perrig, W. J. (2008). Improving fluid intelligence with training on working memory. Proceeding of the National Academy of Science, 105, 6829-6833.

Kirchner, W. K., (1958). Age differences in short-term retention of rapidly changing information. Journal of Experimental Psychology, 55(4), 352-358. doi: $10.1037 / \mathrm{h} 0043688$

Mathy, F., Chekaf, M., \& Cowan, N. (2018). Simple and complex working memory tasks allow similar benefits of information compression. Journal of Cognition, 1(1), 31. doi: $10.5334 /$ joc. 31

Miller, G. A., (1956). The magical number seven, plus or minus two: Some limits on our capacity for processing information. Psychological Review, 63(2), 81-97. doi: $10.1037 / \mathrm{h} 0043158$

Raven, J. C. (1936). Mental tests used in genetic studies: The performance of related individuals on tests mainly educative and mainly reproductive. MSc Thesis of University of London.

Rosenthal, R., (1979). The "File Drawer Problem" and tolerance for null results. Psychological Bulletin, 86(3), 638-641. doi: 10.1037/0033-2909.86.3.638

Schmiedek, F., Hildebrandt, A., Lövdén, M., Lindenberger, U., \& Wilhelm, O., (2009). Complex span versus updating tasks of working memory: The gap is not that deep. Journal of Experimental Psychology: Learning, Memory, and Cognition, 35(4), 1089-1096. doi: 10.1037/a0015730. 
Shelton, J. T., Elliott, E. M., Matthews, R. A., Hill, B. D., \& Grouvier, W. D. (2010). The relationships of working memory, secondary memory, and general fluid intelligence: Working memory is special. Journal of Experimental Psychology: Learning, Memory, and Cognition, 36(3), 813-820. doi: 10.1037/a0019046

Turner, M., \& Engle, R. W., (1989). Is working memory capacity task dependent? Journal of Memory and Language, 28(2), 127-154. doi: 10.1016/0749-596X(89)90040-5

Unsworth, N., Heitz, R.P., Schrock, J.C., \& Engle, R. W., (2005). An automated version of the operation span task. Behavior Research Methods, 37(3), 498-505. doi: 10.3758/BF03192720

Yuan, K., Steedle, J., Shavelson, R., Alonzo, A., \& Oppezzo, M., (2006). Working memory, fluid intelligence, and science learning. Educational Research Review, 1(2), 83-98. doi: 10.1016/j.edurev.2006.08.005 


\section{APPENDIX: HUMAN SUBJECTS IRB APPROVAL}

To:

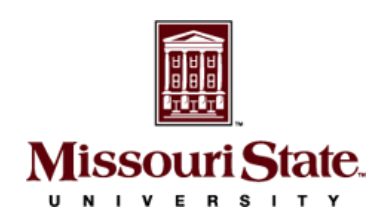

Erin Buchanan

Psychology

RE: Notice of IRB Approval

Submission Type: Initial

Study \#: IRB-FY2018-750

Study Title: Addie Thesis

Decision: Approved

Approval Date: September 4, 2018

Expiration Date: September 4, 2019

This submission has been approved by the Missouri State University Institutional Review Board (IRB) for the period indicated.

Federal regulations require that all research be reviewed at least annually. It is the Principal Investigator's responsibility to submit for renewal and obtain approval before the expiration date. You may not continue any research activity beyond the expiration date without IRB approval. Failure to receive approval for continuation before the expiration date will result in automatic termination of the approval for this study on the expiration date.

You are required to obtain IRB approval for any changes to any aspect of this study before they can be implemented. Should any adverse event or unanticipated problem involving risks to subjects or others occur it must be reported immediately to the IRB.

This study was reviewed in accordance with federal regulations governing human subjects research, including those found at 45 CFR 46 (Common Rule), 45 CFR 164 (HIPAA), 21 CFR $50 \& 56$ (FDA), and 40 CFR 26 (EPA), where applicable.

Researchers Associated with this Project:

PI: Erin Buchanan

Co-PI:

Primary Contact: Addie Wikowsky Other Investigators: 
IRB \#: IRB-FY2018-750

Title: Addie Thesis

Creation Date: 6-13-2018

End Date:

Status: Closed

Principal Investigator: Erin Buchanan

Review Board: MSU

Sponsor:

\section{Study History}

\begin{tabular}{lll}
\hline Submission Type Initial & Review Type Expedited & Decision Approved \\
\hline Submission Type Modification & Review Type Expedited & Decision Approved \\
\hline Submission Type Closure & Review Type Unassigned & Decision
\end{tabular}

\section{Key Study Contacts}

\begin{tabular}{lll}
\hline Member Erin Buchanan & Role Principal Investigator & $\begin{array}{l}\text { Contact } \\
\text { erinbuchanan@missouristate.edu }\end{array}$ \\
\hline Member Addie Wikowsky & Role Primary Contact & $\begin{array}{l}\text { Contact } \\
\text { addie623@live.missouristate.edu }\end{array}$ \\
\hline
\end{tabular}




\section{Initial Submission}

\section{General Information}

What is the full title of the research protocol?

$1 \mathrm{~A}$.

Expertise within Working Memory and Fluid Intelligence

\section{Abstract/Summary}

1B.

Please provide a brief description of the project (no more than a few sentences).

Expertise and working memory studies have been done on various subjects. Very few studies include fluid intelligence and how it is related to expertise. I wish to compare expertise and working memory again, and then see how expertise and fluid intelligence are related.

Who is the Principal Investigator?

This MUST be a faculty or staff member.

$1 \mathrm{C}$

Name: Erin Buchanan

Organization: Psychology

Address: 901 S National Ave , Springfield, MO 65897-0027

Phone: 417-836-5592

Email: erinbuchanan@missouristate.edu

Who is the primary study contact? 
This person may be the Principal Investigator or someone else (faculty, staff, or

1D. student). This person, in addition to the Pl, will be included on all correspondence related to this project.

Name: Addie Wikowsky

Organization: Psychology

Address: 901, S. National Avenue, Springfield, MO 65897-0027

Phone:

Email: addie623@live.missouristate.edu

Select the Co-Principal Investigator(s).

$1 \mathrm{E}$

This MUST be a faculty or staff member. Persons listed as Co-PIs will be required to certify the protocol (in addition to the Pl). This person will also be included on all correspondence related to this project.

Select the Investigator(s).

$1 \mathrm{~F}$

An investigator may be faculty, staff, or student.

If you could not locate personnel using the "Find People" button, please request access at Cayuse Logon Request

For additional help, email irb@missouristate.edu. 


\section{Research Protocol}

\section{Describe the proposed project in a manner that allows the IRB to gain a sense of the project including:}

- the research questions and objectives,

- key background literature (supportive and contradictory) with references, and

- the manner in which the proposed project will improve the understanding of the chosen topic.

-Those who have a higher expertise will have a higher working memory OSPAN scores and higher fluid intelligence Raven scores.

-By having participants who have some kind of expertise in a language can help us understand if they have a higher fluid intelligence and working memory than those in the control condition. -The (OSPAN) created by Turner and Engle (1989). It was designed to test participants working memory. For clarification, working memory can be defined as: the processes involved in examining,

2A. considering, manipulating, and responding to internal and external events (Robinson-Riegler, G., \& Robinson-Riegler, B., 2004). Jaeggi, S., Buschkuehl, M., Jonides, J., \& Perrig, W., (2008) classify fluid intelligence $(G f)$ as a human ability that allows participants to adapt their thinking to the problem at hand regardless of acquired knowledge. A common practice when it comes to testing $G f$ is using the Raven's Advanced Progressive Matrices (RAPM). This is where participants are given a number of different diagrams with different lines and shapes and they have to distinguish which image would come next. The last construct that may affect your working memory or fluid intelligence is expertise. Gobet, F. and Ereku, M. (2016), spoke of Dreyfus and Dreyfus (1988) paper where they categorized expertise as, "fluid, automatic behavior without any conscious control," which is how anyone should think of it. Although there is not a good overall way to test if someone has expertise, most articles just use a median split to separate participants into a novice group, or an expert group (Sattizahn, J.R., Moser, J.S., \& Beilock, S.L., 2016). This may not be the best way to show or categorize a person's expertise, but it is the best we have currently available and that has been used in research. With these three constructs combined, they could help shape how things may get stored in our short-term or long-term memory. They each play an important part in how we view the world around us and evaluate everyday situations.

2B. Check all research activities that apply:

Audio, video, digital, or image recordings 
Biohazards (e.g., rDNA, infectious agents, select agents, toxins)

Biological sampling (other than blood)

Blood drawing

Class Protocol (or Program or Umbrella Protocol)

Data, not publicly available

Data, publicly available

Deception

Devices

Diet, exercise, or sleep modifications

Drugs or biologics

Focus groups

Internet or email data collection

Materials that may be considered sensitive, offensive, threatening, or degrading

Non-invasive medical procedures

Observation of participants

Oral history

Placebo

Record review

Specimen research

Surgical procedures

$\checkmark$ Surveys, questionnaires, or interviews (one-on-one)

Surveys, questionnaires, or interviews (group)

Other 
Describe the procedures and methods planned for carrying out the study. Make sure to include the following:

- site selection,

- the procedures used to gain permission to carry out research at the selected site(s),

- data collection procedures,

- and an overview of the manner in which data will be analyzed.

Provide all information necessary for the IRB to be clear about all of the contact human 2C. participants will have with the project.

The students who signed up on SONA will come into the lab and complete a concent form. They will then get instructions on which tasks they will be performing. The experimental group will complete the OSPAN, RAVEN and the foreign language placement exam. The control group will complete the OSPAN, RAVEN, and a words per minute test. Every other student who comes into the lab will complete the tests in a different order to control for randomization. After all tests are complete, the debriefing will begin.

Materials for experiment and analysis:

Online OSPAN (use P1 to view)

Online RAVEN (use any number as participant number)

Online words per minute test (WPM)

MSU's Foreign Language Placement Exam (password bears1)

Data will be examined using $\mathrm{R}$ Studio and packages included in $\mathrm{R}$.

Attach surveys, questionnaires, and other social-behavioral measurement tools, if applicable.

2D.

OSPAN

Ravens

Typing Test

Placement Exam 
3A. Specify the participant population(s). Check all that apply.

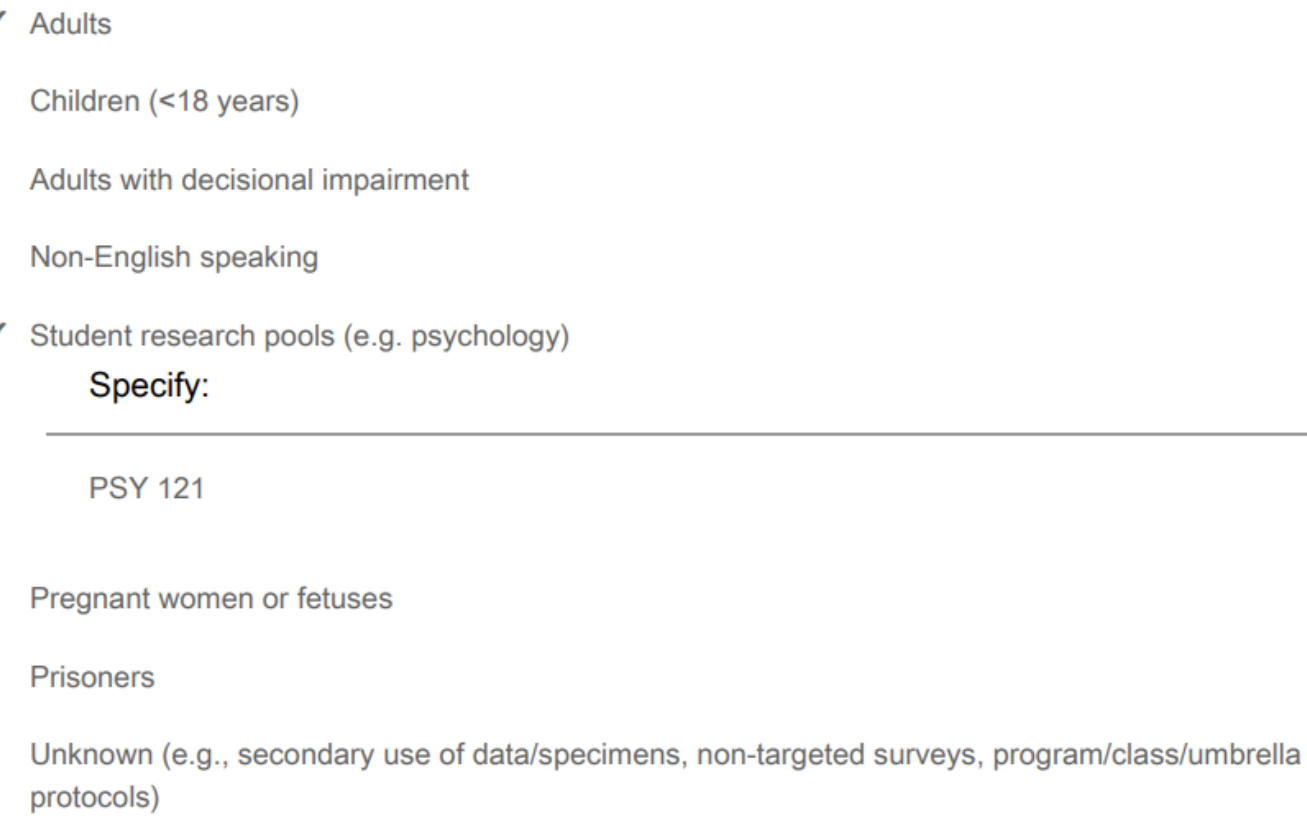

3B. Specify the age(s) of the individuals who may participate in the research.

$18+$

Describe the characteristics of the proposed participants, and explain how the nature of 3C. the research requires/justifies their inclusion.

Participants will be undergraduate students from PSY 121, some will have some sort of expertise in a language other than English, the remainder will be our control group. 
Provide the total number of participants (or number of participant records, specimens, 3D. etc.) for whom you are seeking Missouri State IRB approval.

100 participants

Estimate the time required from each participant, including individual interactions, total time commitment, and long-term follow-up, if any.

3F. Control Group: One time approx. hour to have the participant take the WPM test, OSPAN and RAVEN

Experimental Group: One time approx. hour to have the participant take the placement exam, OSPAN, and RAVEN

No long-term follow-up.

Describe how potential participants will be identified (e.g., advertising, individuals known to investigator, record review, etc.). Explain how investigator(s) will gain access to this

3G. population, as applicable.

We intend to use PSY 121 students so that they may complete their course credit, through MSU's SONA system.

Describe the recruitment process; including the setting in which recruitment will take

$3 \mathrm{H}$. place. Provide copies of proposed recruitment materials (e.g., ads, flyers, website postings, recruitment letters, and oral/written scripts).

MSU's SONA system to have students sign up for a time slot. 
3H.1. Attach recruitment materials, if applicable.

Will participants receive compensation or other incentives (e.g., free services, cash

3I. payments, gift certificates, parking, classroom credit, travel reimbursement, etc.) to participate in the research study?

$\checkmark$ Yes

Describe the incentive, including the amount and timing of all payments.

It will go towards their course credit for PSY 121.

No 


\section{Informed Consent}

From the list below, indicate how consent will be obtained for this study.

$4 \mathrm{~A}$

Check all that apply.

Written/signed consent by the subject

Written/signed consent (permission) for a minor by a Parent or Legal Guardian

Written/signed consent by a Legally Authorized Representative (for adults incapable of consenting).

Request for Waiver of Documentation of Consent (e.g. Verbal Consent, Anonymous Surveys, etc.)

Waiver of parental permission

Consent will not be obtained from subjects (Waiver of Consent)

Describe the consent process including where and by whom the subjects will be approached, the plans to ensure the privacy of the subjects and the measures to ensure that subjects understand the nature of the study, its procedures, risks and benefits and 4B. that they freely grant their consent.

The research will take place at Hill Hall in our lab. Once the subject arrives for their time slot, they will have to sign a consent form with the proper information regarding the study via a Qualtrics Survey.

Attach all copies of informed consent documents (written or verbal) that will be 4B.1. used for this study.

Consent Form.docSample documents: Informed Consent Examples

Attach all copies of assent documents that will be used for this study, if 4B.2. applicable.

Sample documents: Assent Examples 


\section{Risks and Benefits}

Describe all reasonably expected risks, harms, and/or discomforts that may apply to the research. Discuss severity and likelihood of occurrence.

$5 A$.

Consider the range of risks - physical, psychological, social, legal, and economic.

No expected risks except possible fatigue from answering questions, although we expect this to not take longer than a normal in class test.

$5 B$.

Describe the steps that will be taken to minimize risks and the likelihood of harm.

Participants will be allowed to take breaks between tests.

List the potential benefits that participants may expect as a result of this research study. 5C. State if there are no direct benefits to individual participants.

No expected benefits directly to participants.

Describe any potential indirect benefits to future subjects, science, and society.

5D.

By understanding, if there is a link between expertise and your working memory and fluid intelligence, we as a field can provide further research to see how expertise works with other brain functions to optimize learning and knowledge. 
5E. Discuss how risks to participants are reasonable when compared to the anticipated benefits to participants (if any) and the importance of the knowledge that may reasonably be expected to result.

Given the small risks, the benefits outweigh those risks. 


\section{Data Collection}

Missouri State University is committed to keeping data and information secure. Please review the Missouri State Information Security policies. Discuss your project with the MSU Information Security Office or your College's IT support staff if you have questions about how to handle your data appropriately.

\section{Statement of Principal Investigator Responsibility for Data}

The principal investigator of this study is responsible for the storage, oversight, and

6A disposal of all data associated with this study. Data will not be disseminated without the explicit approval of the principal investigator, and identifying information associated with the data will not be shared.

By checking this box, all personnel associated with this study understand and agree to the Statement of Principal Investigator Responsibility for Data.

How will the data for this study be collect/stored?

6B.

Check all that apply.

$\checkmark$ Electronic storage format

On paper

Describe where the data will be stored (e.g., paper forms, flash drives or removeable media, desktop or laptop computer, server, research storage area network, external source). 
6C. The data will be stored on a password protected OneDrive account during the study. The data will be shared on the open science framework website with the submission of any publications.

M Number information will be used to collect the foreign language assessment information to link to the rest of the data. After this information is linked to the dataset, the Mnumbers will be deleted. Otherwise, all participants are given a unique participant id, and no other identifying information will be collected.

Describe the plan to protect the confidentiality of records (e.g., locked office, locked file 6D. cabinet, password-protected computer or files, encrypted data files, database limited to coded data, master list stored in separate location).

Password protected files on a onedrive account.

Describe how data will be disposed of and when disposal will occur.

$6 \mathrm{E}$.

Data will be shared on the open science framework after the data collection is done for dissemination to the larger research community. The data will not be disposed of. the consent form qualtrics will be deleted after a minimum of 5 years, to cover requirements from the American Psychological Association. 
Is this study externally funded?

$7 \mathrm{~A}$.

For example, this research is funded by a source outside Missouri State; a federal agency, non-profit organization, etc.

$$
\text { Yes }
$$

$\checkmark$ No

Potentially (this study is being submitted for funding, but has not yet been awarded)

Is this study internally funded?

7B.

For example, this research is funded by a source inside Missouri State; departmental funds, the Graduate College, etc.

\footnotetext{
Yes

$\checkmark$ No

Potentially (this study is being submitted for funding, but has not yet been awarded)
} 


\section{HIPAA}

Does your study contain protected health information (PHI)?

$8 \mathrm{~A}$.

$\mathrm{PHI}$ is any information in a medical record or designated record set that can be used to identify an individual and that was created, used, or disclosed in the course of providing a a health care service, such as a diagnosis or treatment.

\footnotetext{
Yes

$\checkmark$ No
} 


\section{Supporting Documentation}

Human Subjects Training Certificates

9A.

Attach human subjects training certificates for all listed personnel. To access your training documents, please go to $\mathrm{CITI}$ Training.

buchanan msu citi.pdf

citi addie.pdf

HIPAA Training Certificates

9B.

Attach HIPAA training certificates for all listed personnel, if applicable. To get more information about HIPAA training and/or to access your training documents, please go to HIPAA Information for Researchers.

Informed Consent Documents

9C.

Attach all copies of informed consent documents (written or verbal) that will be used for this study.

Consent Form.docSample documents: Informed Consent Examples

Assent Documents

9D.

Attach all copies of assent documents (written or verbal) that will be used for this study. Sample documents: Assent Examples 
$9 \mathrm{E}$.

Recruitment Tools

Attach copies of proposed recruitment tools.

Surveys/Questionnaires/Other Social-Behavioral Measurement Tools

9F. Attach surveys, questionnaires, and other social-behavioral measurement tools.

OSPAN

Ravens

Typing Test

Placement Exam

Other Documents

$9 G$.

Attach any other documents that have not been specified in previous questions, but are needed for IRB review. 
10. Additional Information

10A. Would you like to add additional information?

Yes
$\checkmark$ No




\section{Modification Submission}

\section{Modification Summary}

Please make changes to the original protocol sections below. In addition, provide a summary of the changes by completing the questions on this page.

A.

To which of the following aspects of research does this modification request apply?

Check all that apply.

Change in personnel

Research design

Risks to participants or others in relation to anticipated benefits

$\checkmark$ Participant selection or recruitment process

Consent process and/or compensation

Methods for documenting consent

Change in supporting documentation or attachments

Potential willingness of research participants to continue to take part in this study

Monitoring of the data being collected

Privacy of the research participants and/or confidentiality of research participants' data

Other

Please provide a brief rationale for each of the changes being requested.

B. 
In order to help reach our desired sample size, we will recruit additional students through professor's courses who are willing to offer extra credit for their participation. 


\section{Closure Submission}

\section{CLOSURE}

If the answer to any of the following questions is "NO," the study must remain open. Please submit a renewal or modification request, if applicable.

For intervention/interaction studies, have all human subjects research activities ended?

1. For example - all enrolled subjects have completed the research interaction/intervention, no identifiable data or identified specimens are being collected, the data has been "locked," and any data analysis or manuscript preparation has been completed.

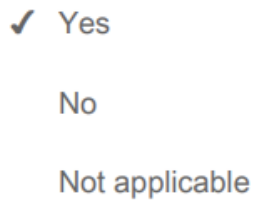

Has all identifiable data for the research collected solely from existing records been coded, de-identified, and the code "link" been destroyed?

2.

NOTE: Data analysis or manuscript preparation may continue with the de-identified data only if the data cannot be linked back to individual research subjects.

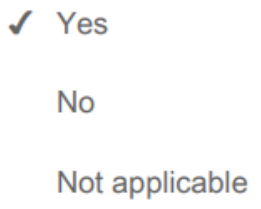


3. Has the sponsor of the study approved study closure with Missouri State University?

Yes
No
$\checkmark$ Not applicable

4. Was the study conducted in accordance with all applicable federal, state, and local regulations and policies regarding the protection of human subjects in research?

$\checkmark$ Yes
No
Not applicable

5. Will study records be retained for a minimum of 3 years, or longer based on the contract, federal, or sponsor requirements?

$\checkmark$ Yes

No

Not applicable

Have all findings that could have a potentially negative impact on participant safety been reported to the IRB? 
6.

For example - serious adverse events, unanticipated problems, complaints, audit findings, etc.

Yes

No

$\checkmark$ Not applicable

7. I understand my responsibility to maintain the confidentiality of the data and/or specimens.

$\checkmark$ Yes

No

Not applicable

8. I understand I must obtain IRB approval before accessing data or stored specimens for future research.

$\checkmark$ Yes

No

Not applicable

9. If needed, please provide any additional comments regarding this closure request. 